\title{
Frequiência de Neoplasia Intra-epitelial Cervical em Portadoras do Virus da Imunodeficiência Humana
}

\author{
Frequency of Cervical Intraepithelial Neoplasia in Human \\ Immunodeficiency Virus-infected Women
}

Antonio Pedro Flores Auge ${ }^{1}$, Sebastião Piato ${ }^{1}$, Armando Brites Frade ${ }^{2}$, Roberto Pinto Paes ${ }^{1}$

Cleide Maria Calmon de Moura ${ }^{3}$, Alba Lúcia Dias dos Santos ${ }^{3}$, Altamir Vaz ${ }^{2}$

\begin{abstract}
RESUMO
Objetivo: verificar a freqüencia de neoplasia intra-epitelial cervical (NIC) em mulheres infectadas pelo virus da imunodeficiência humana (HIV).

Métodos: foram estudadas 99 mulheres HIV-soropositivas; o diagnóstico da infeccão pelo HIV foi realizado por meio de dois testes ELISA, complementados por teste Western blot ou de imunofluorescência indireta. Como grupo controle foram analisadas 104 mulheres que não apresentavam positividade no teste ELISA. Em ambos os grupos o rastreamento de NIC foi realizado por meio da associação de colpocitologia oncológica e colposcopia. Nos casos em que a colposcopia revelou existência de zonas de transformação anormal, o diagnóstico de NIC foi realizado mediante biopsia dirigida, complementada ou não por conização.

Resultados: em 15 das 99 pacientes do grupo de estudo (15,2\%) foi encontrada neoplasia intra-epitelial cervical, sendo dez casos de NIC I, um de NIC II e quatro de NIC III. Entre as 104 mulheres do grupo controle, quatro $(3,8 \%)$ eram portadoras de neoplasia intra-epitelial cervical, encontrando-se um caso de NIC I e três de NIC III.

Conclusão: a análise comparativa dos resultados evidenciou que a freqüência de neoplasia intra-epitelial cervical foi significantemente mais elevada entre as pacientes infectadas pelo HIV.
\end{abstract}

PALAVRAS-CHAVE: AIDS. Colo uterino: lesões pré-neoplásicas. Colposcopia. Colpocitologia.

Introdução

Tendo em vista a importância do papilomavirus humano (HPV) na gênese das neoplasias intra-epiteliais cervicais (NIC), tem havido interesse de muitos autores em investigar se a imunodepressão ocasionada pelo vírus da imunodeficiência humana (HIV) constituiria em fator de risco para o desenvolvimento dessas lesões do colo uterino. Numerosos estudos epidemiológicos têm evidenciado que nos grupos de mulheres HIV-soropositivas observa-se maior incidência de infecção do trato genital inferior pelo $\mathrm{HPV}^{1-6}$.

${ }^{1}$ Faculdade de Ciências Médicas da Santa Casa de São Paulo

${ }^{2}$ Complexo Hospitalar Padre Bento de Guarulhos

${ }^{3}$ Secretaria Municipal de Saúde de Guarulhos

Correspondência:

Antonio Pedro Flores Auge

Rua Joaquim Floriano, 72 conj 88 - Itaim Bibi

04534-000 - São Paulo - SP

FAX: (11) 3849-7733/ 4848
Paralelamente a esses estudos, há na literatura vários relatos mostrando freqüência significativamente aumentada de NIC entre as mulheres infectadas pelo HIV, especialmente entre aquelas que apresentam algum grau de imunodepressão ${ }^{7-10}$. Em nosso meio não encontramos publicações acerca da freqüência de NIC em mulheres HIV-soropositivas.

No rastreamento das NIC em mulheres infectadas pelo HIV, a colpocitologia oncológica apresenta baixa sensibilidade, fato este responsável por elevados índices de resultados falsonegativos ${ }^{11,12}$. Por meio do estudo de 13 pacientes, nas quais a histologia evidenciou a presença de neoplasia intra-epitelial cervical, Tweddel et al. ${ }^{13}$ constataram que em três delas $(23 \%)$ o exame colpocitológico revelou-se negativo.

O objetivo do presente estudo foi avaliar a freqüência de NIC em grupo de mulheres portadoras do HIV em nosso meio com a utilização de metodologia de rastreamento que associou col- 
pocitologia oncológica e exame colposcópico.

\section{Pacientes e Métodos}

O grupo de estudo do presente trabalho é constituído por 99 mulheres portadoras do HIV. Foram consideradas HIV-soropositivas as pacientes que apresentaram dois testes imunoenzimáticos de ELISA (enzyme-linked immunosorbent assay) positivos, complementados com testes Western blot ou de imunofluorescência indireta positivos. Para formação deste grupo foram excluídas pacientes com idade inferior a 17 anos e superior a 51 anos, assim como aquelas portadoras de carcinoma cervical invasivo.

Como grupo controle foram estudadas 104 mulheres não infectadas pelo HIV. A infecção pelo referido virus foi descartada por meio de teste imunoenzimático ELISA. Os critérios de exclusão para a formação deste grupo foram os mesmos adotados em relação ao grupo de estudo.

Todas as pacientes estudadas assinaram termo de anuência, após serem informadas da natureza da pesquisa. A execução do presente trabalho foi aprovada pelas Comissões de Ética dos respectivos Serviços.

Para o rastreamento das NIC, tanto no grupo de estudo como no grupo controle, utilizouse associação de colpocitologia oncológica e colposcopia. A primeira foi realizada pelas técnicas habituais de colheita de material seguida da coloração pelo método de Papanicolaou e exame microscópico dos esfregaços. Em todas as pacientes foi praticada colheita triplice de material, isto é, do recesso vaginal posterior, exocérvice e canal endocervical. A leitura das lâminas foi feita sempre pelo mesmo patologista. Os esfregaços foram inicialmente classificados segundo o método estabelecido por Papanicolaou e Traut (1943) e, posteriomente, correlacionados com a nomenclatura preconizada por Richart ${ }^{14}$.

Os exames colposcópicos, realizados com aparelhagem e técnica habituais, tanto no grupo de estudo como no grupo controle, foram praticados sempre pelo mesmo especialista, que desconhecia o estado das pacientes em relação à presença ou ausência de infecção pelo vírus HIV.

Em 51 pacientes do grupo de estudo e em outras 24 do grupo controle a colposcopia revelou a presença de zonas de transformação anormal (ZTA) ou outras lesões que sugeriram exame histopatológico, ao passo que em 48 pacientes do grupo de estudo e em 80 do grupo controle o colo uterino apresentou-se bem epitelizado ou com alterações que não justificaram avaliação histopatológica.

Nas pacientes em que os exames colposcópicos revelaram ZTA, praticou-se biopsia dirigida com auxílio de pinça de Gaylor-Medina. Nos casos em que o exame histopatológico dos espécimes obtidos pela biopsia revelou NIC I, nenhum outro procedimento foi realizado. Naqueles em que revelou NIC II ou NIC III, realizou-se conização do colo uterino, para descartar a presença de carcinoma invasivo.

Os exames histopatológicos dos materiais obtidos, tanto pela biopsia dirigida como pela conização, foram realizados pelo mesmo patologista. A classificação das neoplasias intraepiteliais cervicais encontradas baseou-se nos critérios preconizados por Scully ${ }^{15}$ e referendados pela Organização Mundial de Saúde em 1994.

Os dados deste estudo foram processados em Epi-Info v6.01. A descrição, os cruzamentos e os testes estatísticos foram obtidos por meio deste programa. Os testes realizados de acordo com a natureza das variáveis foram os seguintes: $\chi^{2}$, teste exato de Fisher e teste $t$ de Student, para a comparação de duas amostras independentes. Em todos os testes, fixamos um alfa de 0,05 ou seja, foi considerado $5 \%$ o nível de rejeição da hipótese de nulidade.

\section{Resultados}

Na Tabela 1 é exposta a freqüência de neoplasia intraepitelial cervical nas 99 pacientes do grupo de estudo e nas 104 pacientes do grupo controle. Verifica-se que entre as pacientes do grupo de estudo, a freqüência de NIC foi quatro vezes maior que nas pacientes do grupo controle. O teste estatístico $\left(\chi^{2}\right)$ indicou que a diferença encontrada entre os dois grupos possui significância.

Tabela 1 - Freqüência de neoplasia intraepitelial cervical (NIC) nas 99 pacientes do rupo de estudo enas 104 pacientes do grupo controle.

\begin{tabular}{lcccccc}
\hline NIC & \multicolumn{2}{c}{ Grupo de estudo } & \multicolumn{2}{c}{ Grupo controle } & \multicolumn{2}{c}{ Total } \\
& Freqüência & $\%$ & Freqüência & $\%$ & Freqüência & $\%$ \\
\hline Positivo & 15 & 15,2 & 4 & 3,8 & 19 & 9,3 \\
Negativo & 84 & 84,8 & 100 & 96,2 & 184 & 90,7 \\
Total & 99 & 100,0 & 104 & 100,0 & 203 & 100,0 \\
\hline p<0,05 & & & & & &
\end{tabular}

Na Tabela 2 estão distribuídos os casos de 
NIC encontrados nos dois grupos estudados, de acordo com a avaliação histopatológica. Nota-se que entre as pacientes do grupo de estudo foi diagnosticado NIC I em 10 espécimes de 15 avaliados, um NIC II e quatro NIC III.

Tabela 2 - Graus de neoplasia intraepitelial cervical (NIC) nas pacientes do grupo de estudo e grupo controle.

\begin{tabular}{lcc}
\hline & Grupo de estudo & Grupo controle \\
\hline $\mathrm{NICI}$ & 10 & 01 \\
$\mathrm{NIC} \mathrm{II}$ & 01 & - \\
$\mathrm{NIC} \mathrm{III}$ & 04 & 03 \\
Total & 15 & 04 \\
\hline
\end{tabular}

A distribuição dos resultados da colpocitologia oncológica e do exame histopatológico dos espécimes obtidos do colo uterino das 15 pacientes portadoras de NIC do grupo de estudo é apresentada na Tabela 3. Também observa-se a distribuição das alterações citoarquiteturais, tais como coilocitose, disqueratose, discariose e multinucleação, identificadas no exame histopatológico, nominadas por expressão viral do HPV, das mesmas pacientes.

Tabela 3 - Distribuição dos resultados de colpocitologia oncológica, histopatologia e expressão do HPV nas 15 pacientes portadoras de NIC do grupo de estudo.

\begin{tabular}{|c|c|c|}
\hline $\mathrm{N}^{\circ}$ & Colpocitologia oncológica & Histopatologia \\
\hline 4 & $\mathrm{NICl}$ & NIC III \\
\hline 9 & Inflamatória & $\mathrm{NICI}+\mathrm{HPV}$ \\
\hline 12 & $\mathrm{NIC} \mathrm{III}$ & NIC III \\
\hline 17 & Inflamatória & $\mathrm{NICI}+\mathrm{HPV}$ \\
\hline 18 & $\mathrm{NICl}$ & $\mathrm{NICI}+\mathrm{HPV}$ \\
\hline 27 & $\mathrm{NICI}+\mathrm{HPV}$ & $\mathrm{NICI}+\mathrm{HPV}$ \\
\hline 30 & Inflamatória & $\mathrm{NIC} \mathrm{III} \mathrm{+} \mathrm{HPV}$ \\
\hline 39 & $\mathrm{NICI}+\mathrm{HPV}$ & $\mathrm{NIC} \mathrm{III} \mathrm{+} \mathrm{HPV}$ \\
\hline 47 & Normal & $\mathrm{NICI}+\mathrm{HPV}$ \\
\hline 63 & Inflamatória & $\mathrm{NIC} \|+\mathrm{HPV}$ \\
\hline 65 & Inflamatória & $\mathrm{NICI}+\mathrm{HPV}$ \\
\hline 76 & $\mathrm{NICI}+\mathrm{HPV}$ & $\mathrm{NICI}+\mathrm{HPV}$ \\
\hline 86 & Inflamatória & $\mathrm{NICI}+\mathrm{HPV}$ \\
\hline 91 & $\mathrm{NICI}+\mathrm{HPV}$ & $\mathrm{NICI}+\mathrm{HPV}$ \\
\hline 97 & Inflamatória & $\mathrm{NICl}+\mathrm{HPV}$ \\
\hline
\end{tabular}

A citologia revelou-se normal em uma paciente e inflamatória em sete das quinze pacientes do grupo de estudo. Em todas essas, a avali- ação histopatológica evidenciou NIC e alterações citoarquiteturais do HPV, que só não foram demonstradas em duas pacientes portadoras de NIC III.

\section{Discussão}

Alguns estudos têm evidenciado que a freqüência de infecção pelo papilomavirus humano está relacionada com comprometimento pelo HIV $^{1,2,5,6}$

Em investigação que relacionou 344 portadoras do virus da imunodeficiência humana e 325 mulheres HIV-soronegativas, nas quais foram utilizados colposcopia e teste do DNA do $\mathrm{HPV}$, Sun et al. ${ }^{4}$ verificaram significativa prevalência de infecção pelo HPV nas mulheres do primeiro grupo. Enquanto a taxa de infecção pelo papilomavirus humano foi de $60 \%$ entre as mulheres HIV-soropositivas, a encontrada entre as mulheres do grupo controle foi de $36 \%$.

No presente trabalho constatamos que havia indicação de infecção pelo papilomavírus humano em 13 dos 15 casos $(86,7 \%)$ de NIC encontrados no grupo de estudo, ao passo que dos 4 casos com NIC presentes no grupo controle, encontraram-se alterações citoarquiteturais sugestivas de infecção pelo HPV em três (75\%).

Baseados no clássico estudo de Sillman et al. ${ }^{16}$, no qual se demonstrou aumento de risco para o aparecimento de infecção pelo HPV em mulheres imunodeprimidas devido ao uso de drogas e quimioterapia, alguns autores procuraram verificar a possivel correlação entre a imunodepressão das portadoras do HIV e a freqüência de comprometimento do colo uterino pelo papilomavirus humano ${ }^{7,11,17,18}$.

Johnson et al. ${ }^{19}$, constataram que a incidência de infecção pelo HPV foi cinco vezes mais elevada entre as mulheres HIV-soropositivas que apresentavam niveis de linfócitos $\mathrm{CD}^{+}$abaixo de $200 / \mathrm{mm}^{3}$ quando comparadas com mulheres HIV-soropositivas imunocompetentes.

Outro fator que tem sido responsabilizado pela maior incidência de infecção pelo HPV é a depleção das células de Langerhans do colo uterino em mulheres HIV-soropositivas imunodeprimidas. Investigação realizada por Spinillo et al. ${ }^{20}$ revelou queda significativa do número médio de células de Langerhans em mulheres infectadas pelo HIV. O estudo revelou ainda que a presença de infecção cérvico-uterina pelo HPV teve relação positiva com o grau de depleção das células de Langerhans.

Finalmente cabe assinalar que investiga- 
ções com técnicas de biologia molecular admitem que o gene regulador Tat, presente no RNA do HIV, interage com o gene E2 do papilomavirus humano, para intensificar a replicação deste independentemente da queda da imunidade ${ }^{21}$.

$\mathrm{Na}$ introdução deste estudo fizemos referência ao fato de que a colpocitologia oncológica apresenta menor sensibilidade para o rastreamento das neoplasias intra-epiteliais cervicais entre as mulheres HIV-soropositivas. No nosso estudo o exame citopatológico apresentou-se negativo em oito das 15 pacientes $(52,8 \%)$ do grupo de estudo. Acredita-se que os resultados falso-negativos relacionem-se com descamação alterada das células da mucosa cervical e com dificuldade para identificar células displásicas, devido a processos inflamatórios ocasionados pela presença de alterações causadas por outros patógenos sexualmente transmissíveis ${ }^{11}$.

Baseado no fato de que a avaliação citológica isolada freqüentemente falha para realizar a detecção das NIC, o "American College of Obstetricians and Gynecologists" (ACOG) estabeleceu, em 1993, a necessidade da associação do exame colposcópico ao teste de Papanicolaou. Em relação às pacientes HIV-soropositivas que apresentam contagem de linfócitos $\mathrm{CD}^{+}$ superior a $200 / \mathrm{mm}^{3}$, o ACOG preconiza teste de Papanicolaou e exame colposcópico a cada seis meses. Naquelas em que os valores são inferiores ao mencionado, recomenda exame citológico a cada três meses e colposcopia a cada seis meses. No presente trabalho seguimos esta orientação.

Tendo em vista que a presente investigação comprovou serem as portadoras do virus HIV, em nosso meio, de alto risco para o desenvolvimento das neoplasias intra-epiteliais cervicais e que a colpocitologia isolada falha em grande parte dos casos para o rastreamento destas lesões, entendemos que a vigilância das mulheres HIVsoropositivas deva ser realizada com breves intervalos e que o rastreamento das NIC seja feito através da associação da colpocitologia oncológica e da colposcopia. Somos de opinião que as recomendações do ACOG, acima referidas, são adequadas para atender esses objetivos.

\section{SUMMARY}

Purpose: to verify the frequency of cervical intraepithelial neoplasia in human immunodeficiency virus (HIV) - infected women.

Methods: ninety-nine HIV-seropositive women were studied. The diagnosis of the HIV infection was established through two ELISA tests complemented by Western blot test or indirect immunofluorescence test. As control group, 104 women whose ELISA test was not positive were analyzed. The investigation of cervical intraepithelial neoplasia was achieved by association of Pap smear and colposcopy in both groups. In the cases where colposcopy revealed existence of abnormal transformation zones, NIC diagnosis was obtained through colposcopy-guided biopsy complemented or not by conization.

Results: cervical intraepithelial neoplasia was found in 15 of the 99 patients $(15.2 \%)$, and among them there were ten NIC I, one NIC II and four NIC III. Among the 104 women of the control group, four presented cervical intraepithelial neoplasia (3.8\%), one being NIC I and three NIC III.

Conclusion: the comparative analysis of the results showed that the frequency of cervical intraepithelial neoplasia was significantly higher among those patients infected with HIV.

KEY WORDS: AIDS. HIV. Uterine cervix: preneoplastic lesions. Colposcopy. Pap smear.

\section{Referências}

1. Kreiss JK, Kiviat NB, Plummer FA, et al. Human immunodeficiency virus, human papillomavirus, and cervical intraepithelial neoplasia in Nairobi prostitutes. Sex Transm Dis 1992; 19:54-9.

2. Laga M, Icenogle JP, Marsella R, et al. Genital papillomavirus infection and cervical dysplasia - opportunistic complications of HIV infection. Int J Cancer 1992; 50:45-8.

3. Zarcone R, Cardone G, Bellini P, Carfora E, Fortuna $\mathrm{G}$, Raucci F. Incidenza dell'infezione da HPV e della CIN in donne HIV-positive. Minerva Ginecol 1995; 47:477-80.

4. Sun XW, Ellerbrock TV, Lungu O, Chiasson MA, Bush TJ, Wright TC Jr. Human papillomavirus infection in human immunodeficiency virusseropositive women. Obstet Gynecol 1995; 85:680-6.

5. Calore EE, Cavalieri MJ, Shirata NK, Araújo MF. Papillomavirus in cervicovaginal smears of women infected with human immunodeficiency virus. São Paulo Med J 1995; 113:1009-11.

6. Motti PG, Dalabetta GA, Daniel RW, et al. Cervical abnormalities, human papillomavirus, and human immunodeficiency virus infections in women in Malawi. J Infect Dis 1996; 173:714-7. 
7. Schäfer A, Friedmann W, Mielke M, Schwartländer B, Koch MA. The increased frequency of cervical dysplasia-neoplasia in women infected with the human immunodeficiency virus is related to the degree of immunosuppression. Am J Obstet Gynecol 1991; 164:593-9.

8. Maggwa BN, Hunter DJ, Mbugua S, Tukei P, Mati JK. The relationship between HIV infection and cervical Intraepithelial neoplasia among women attending two family planning clinics in Nairobi, Kenya. AIDS 1993; 7:733-8.

9. Wright TC Jr, Moscarelli RD, Dole P, Ellerbrock TV, Chiasson MA, Vandevanter N. Significance of mild cytologic atypia in women infected with human immunodeficiency virus. Obstet Gynecol 1996; 87:515-9.

10.Bongain A, Rampal A, Durant J, Michiels JF, Dellamonica P, Gillet JY. Cervical intraepithelial neoplasia in women infected with human immunodeficiency virus. Eur J Obstet Gynecol Reprod Biol 1996; 65:195-9.

11. Maiman M, Tarricone N, Vieira J, Suarez J, Serur E, Boyce JG. Colposcopic evaluation of human immunodeficiency virus-seropositive women. Obstet Gynecol 1991; 78:84-8.

12.Fink MJ, Früchter RG, Maiman M, et al. The adequacy of cytology and colposcopy in diagnosing cervical neoplasia in HIV-seropositive women. Gynecol Oncol 1994; 55:133-7.

13.Tweddel G, Heller P, Cunnane M, Multhaupt H, Roth K. The correlation between HIV seropositivity, cervical dysplasia, and HPV subtypes 6/11, 16/ 18, 31/33/35. Gynecol Oncol 1994; 52:161-4.

14. Richart RM. Historia natural de la neoplasia cervical intraepithelial. Clin Obstet Ginecol 1967; 10:74884.
15. Scully RE, Bonfiglio TA, Kurman RJ, Silverberg SG, Wilkinson EJ. Histological typing of female genital tract tumours. $2^{\text {nd }}$ ed. Berlin: SpringerVerlag; 1994. p.189. (World Health Organization. International Histological Classification of Tumours).

16.Sillman F, Stanek A, Sedlis A, et al. The relationship between human papillomavirus and lower genital intraepithelial neoplasia in immunosuppressed women. Am J Obstet Gynecol 1984; 150:300-8.

17.Adachi A, Fleming I, Burk RD, Ho GY, Women with human immunodeficiency virus infection and abnormal Papanicolaou smears: a prospective study of colposcopy and clinical outcome. Obstet Gynecol; 81:372-7.

18.Spinillo A, Tenti P, Zappatore R, et al. Prevalence, diagnosis and treatment of lower genital neoplasia in women with human immunodeficiency virus infection. Eur J Obstet Gynecol Reprod Biol 1992; 43:235-41.

19.Johnson JC, Burnett AF, Willet GD, Young MA, Doniger J. High frequency of latent and clinical human papillomavirus cervical infection in immunocompromised human immunodeficiency virus-infected women. Obstet Gynecol 1992; 79:321-7.

20.Spinillo A, Tenti P, Zappatore R, De Seta F, Silini E, Guaschino S. Langerhans' cell counts and cervical intraepithelial neoplasia in women with human immunodeficiency virus infection. Gynecol Oncol 1993; 48:210-3.

21.Vernon SD, Hart CE, Reeves WC, Icenogle JP. The HIV-1 tat protein enhances E2-dependent human papillomavirus 16 transcription. Virus Res 1993; 27:133-45.

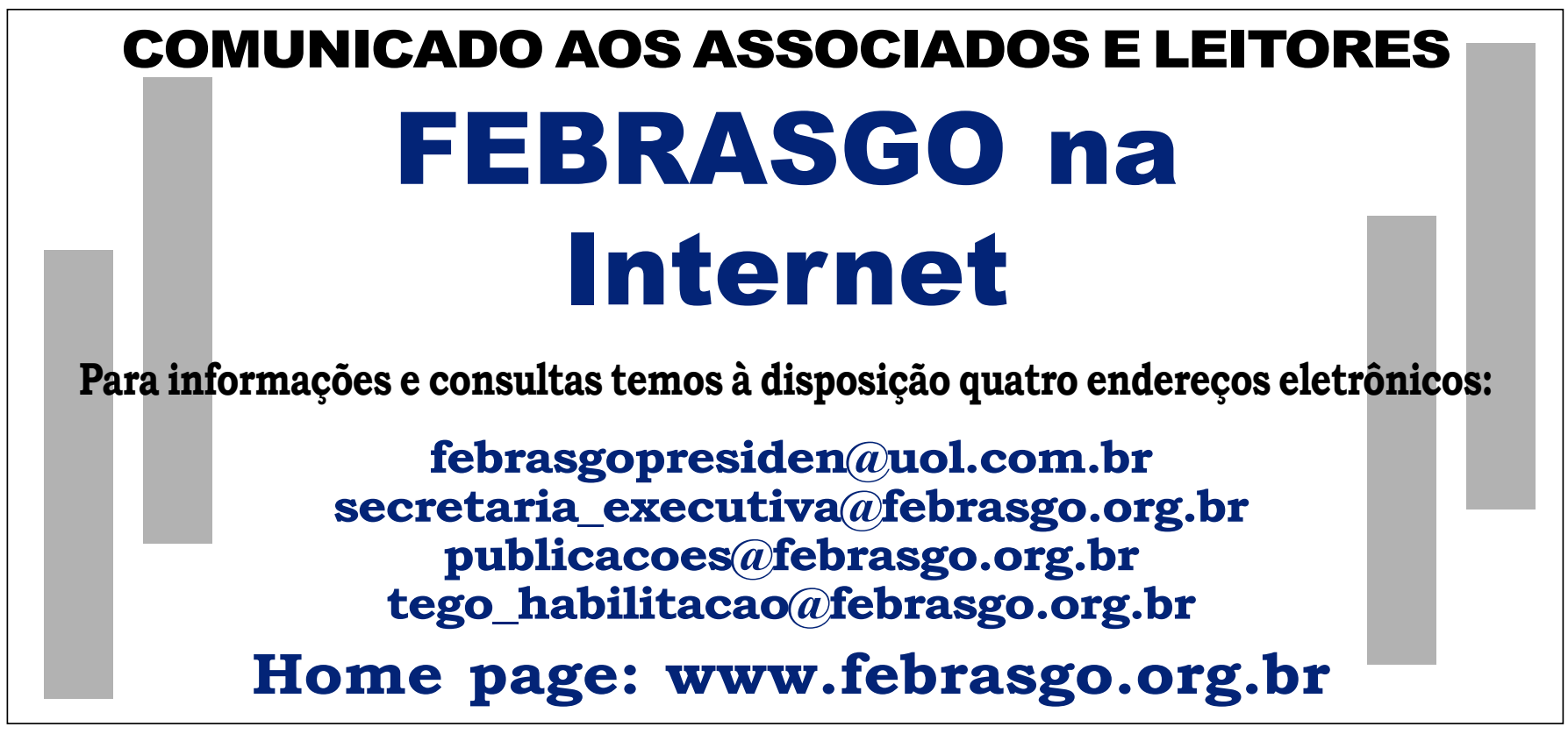

